\title{
EL CEMENTERIO DE LA ISLA DEL REY
}

\author{
JORGE JOAQUÍN PRIETO SÁNCHEZY JOSÉ Ma GIL HERNÁNDEZ \\ Grupo de Regulares de Melilla ${ }^{\circ} 52$
}

Se refleja en este anexo un trabajo realizado por el teniente Jorge Joaquín Prieto Sánchez y redactado y compilado por el brigada José María Gil Hemández. En él se recogen minuciosamente las referencias a todas las sepulturas visibles en el cementerio de la isla del Rey en las Chafarinas, transcribiendo sus leyendas y situándolas sobre un croquis.

Se reflejan un total de 63 sepulturas, todas sobre el suelo, que son el total de enterramientos visibles en la actualidad.

El primer enterramiento del que hay constancia en las lápidas se realizó en 1886 y el último en 1926.

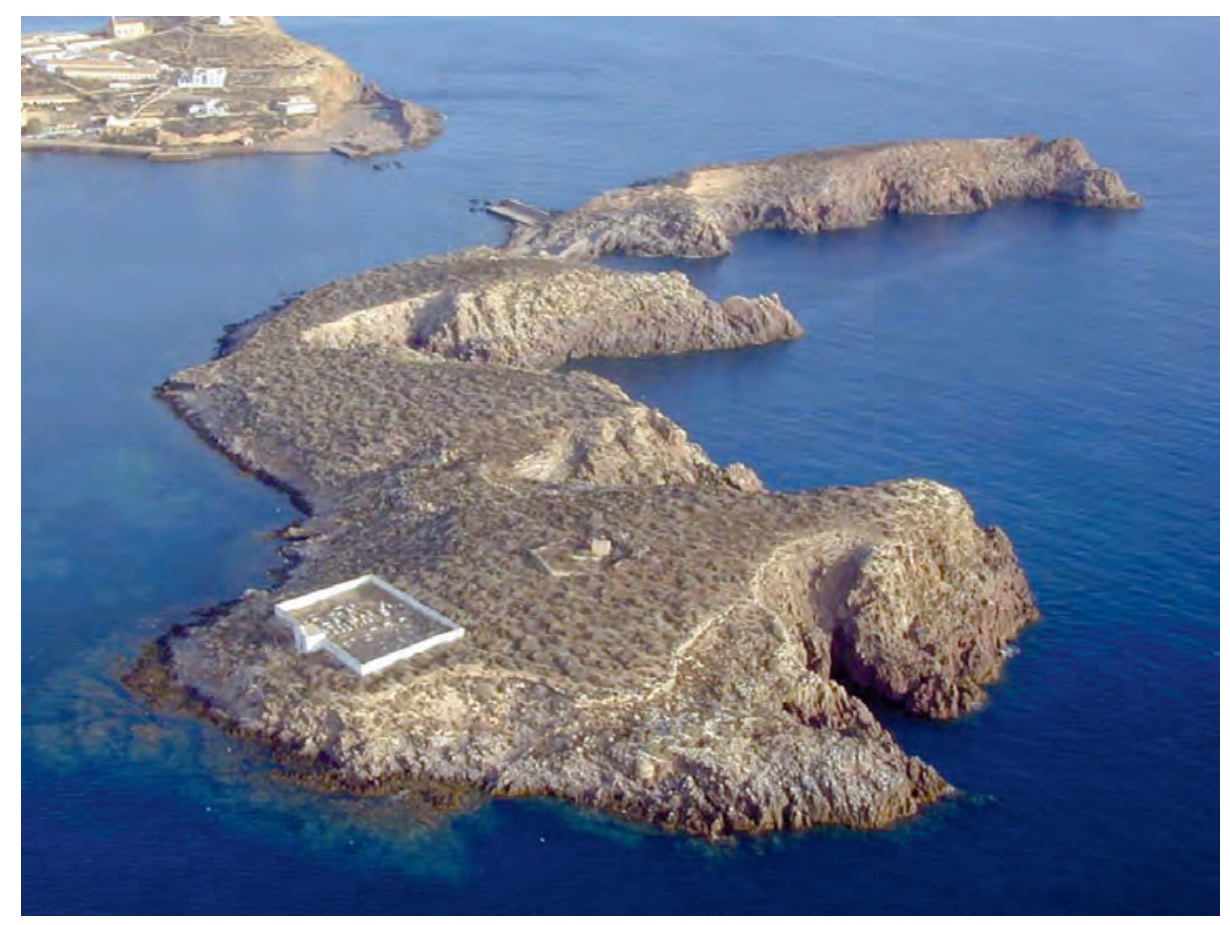

Vista de la isla del Rey con su cementerio en primer plano. 


\section{Relación de sepulturas:}

1.- sin lápida o ilegible

2.- sin lápida o ilegible

3.- sin lápida o ilegible

4.- sin lápida o ilegible

5.- Da Asunción García Polo, viuda de Oses $† 28$ de agosto de 1925 a los 80 años, recuerdo de sus hijos.

6.- sin lápida o ilegible

7.- sin lápida o ilegible

8.- sin lápida o ilegible

9.- D.O.M. El Señor D. Francisco Oses Cortés † El 13 de Noviembre de 1908 a los 67 años R.I.P. recuerdo de su esposa e hijos.

10.- D.O.M. Ma Josefa Del Rio De Vidal. 19 de noviembre $1860 † 12$ de junio de 1909. R.I.P. Recuerdo de su esposo.

11.- la niña Raf aela Mesa Capar ros † 20 octubr e 1921 a los 14 meses . Recuerdo de sus padres y hermanos.

12.- sin lápida o ilegible

13.- sin lápida o ilegible

14.- sin lápida o ilegible

15.- sin lápida o ilegible

16.- sin lápida o ilegible

17.- sin lápida o ilegible

18.- Descansa en el señor la señorita $M^{a}$ del Pilar Martín Valero. Maestra nacional de Chafarinas $\dagger$ el 22 de julio de 1927 a los 44 años, recuerdo de sus padres y hermanos.

19.- sin lápida o ilegible

20.- sin lápida o ilegible

21.- sin lápida o ilegible

22.- sin lápida o ilegible

23.- sin lápida o ilegible

24.- sin lápida o ilegible

25.- sin lápida o ilegible

26.- sin lápida o ilegible

27.- sin lápida o ilegible

28.- sin lápida o ilegible 
29.- sin lápida o ilegible

30.- sin lápida o ilegible

31.- sin lápida o ilegible

32.- sin lápida o ilegible

33.- sin lápida o ilegible

34.- sin lápida o ilegible

35.- sin lápida o ilegible

36.- dibujo de un ángel. La niña Rosa Oses García.Falleció 20 de noviembre 1886, a los 29 meses. Recuerdo de sus padres.

37.- sin lápida o ilegible

38.- sin lápida o ilegible

39.- sin lápida o ilegible

40.- sin lápida o ilegible

41.- sin lápida o ilegible

42.- la niña Dolor es Llobet y de F ortuny. Subió al cielo el 20 de marzo de1922 a los 23 meses. Recuerdo de sus...(falta parte de la lápida)

43.- sin lápida o ilegible

44.- sin lápida o ilegible

45.- Salvador López Montes $† 9$ de marzo de 1924. Recuerdo de sus padres y hermanos.

46.- sin lápida o ilegible

47.- la niña Enriqueta Sánchez Robles. Subió al cielo el 16 de agosto de 1926 a los 13 meses. Recuerdo de sus padres y hermanos.

48.- el niño Pepito Sánchez robles. Subió al cielo el 28 de junio de 1923. Recuerdo de sus padres y hermanos. "J. Sáenz Lerchundi, Melilla”

49.- sin lápida o ilegible

50.- sin lápida o ilegible

51.- sin lápida o ilegible

52.- sin lápida o ilegible

53.- la niña Pilar Zaldívar Sánchez, subió al cielo 15 de noriembre de 1922 a los 30 meses. Recuerdo de sus padres y hermanos.

54.- sin lápida o ilegible

55.- El niño P epito Oses Huer tas. Subió al cielo 28 ma yo 1924 a los 8 meses. (Falta parte de la lápida)

56.- sin lápida o ilegible

57.- sin lápida o ilegible 
58.- sin lápida o ilegible

59.- sin lápida o ilegible

60.- Elena Muñoz González, 24-08-1929. A los 3 años y 3 meses.

61.- sin lápida o ilegible

62.- sin lápida o ilegible

63.- $\mathrm{D}^{\mathrm{a}}$ Catalina Bera, natural de Algeciras, nació el 8 de febr ero de 1850 , falleció el 18 de julio de 1910,recuerdo de sus hijosAntonio Morilla y ManuelAttias.

\section{Tumbas Sin numeración}

La niña Elvira Cerdeña Canovas, subió al cielo el día 23 de diciembr e de 1927 a los 2 meses. Recuerdo de sus padres.

- Dolores Vidal Iglesias † 1910, esposa de Rafael Morán de Alcalá.

- D.O.M. Aurora Trigueros González, † 30 enero 1911 a los 30 años. RIP recuerdo de su madre y sobrinos.

- D.O.M. el señor D. Severiano León Chao, falleció 14 diciembre ... a los 47 años. R.I.P.

-... restos mortales de D. Raimundo Bartolomé Pascual, vecino de esta plaza $\uparrow 14$ febrero 1898. Rogad a Dios por el

- D. Mahón a su compañero D. Manuel ......YAhumada......19....D.E.P.

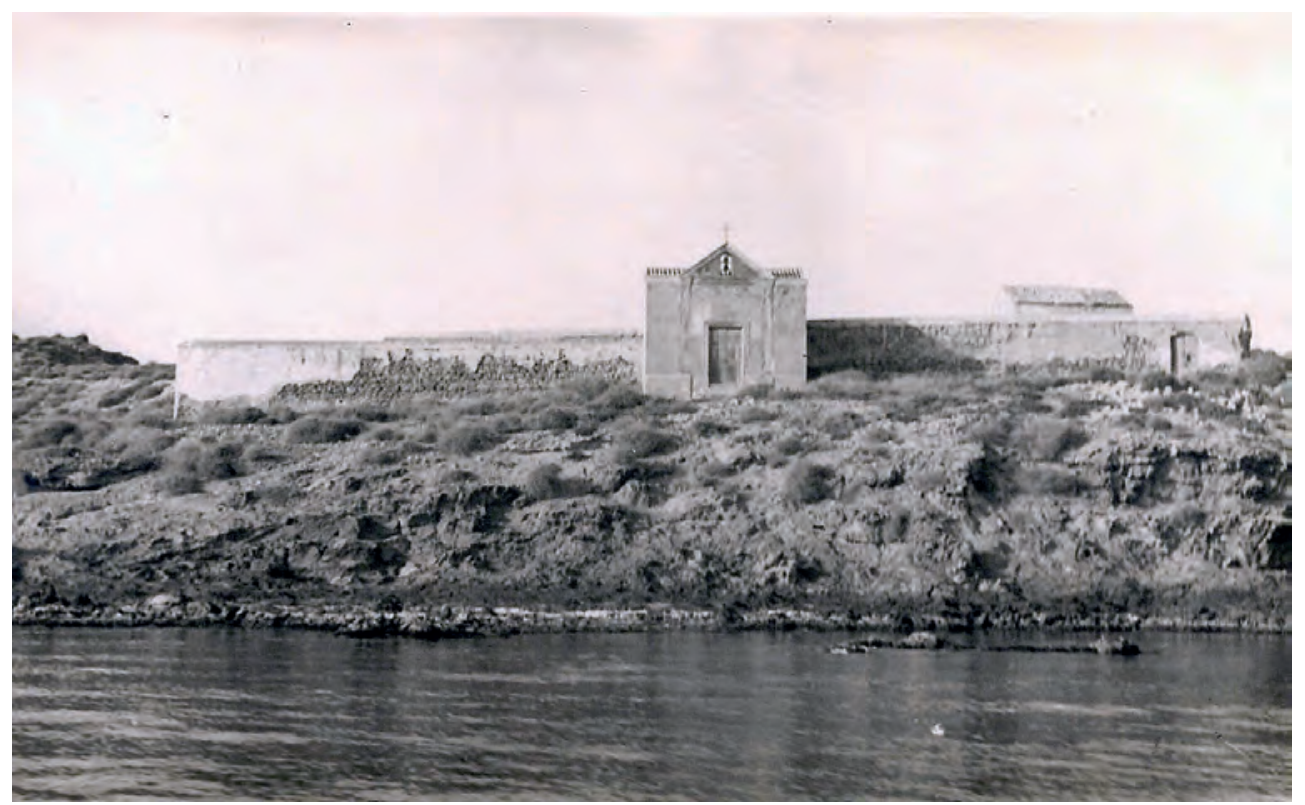

Vista del cementerio desde el mar. AHCM. 


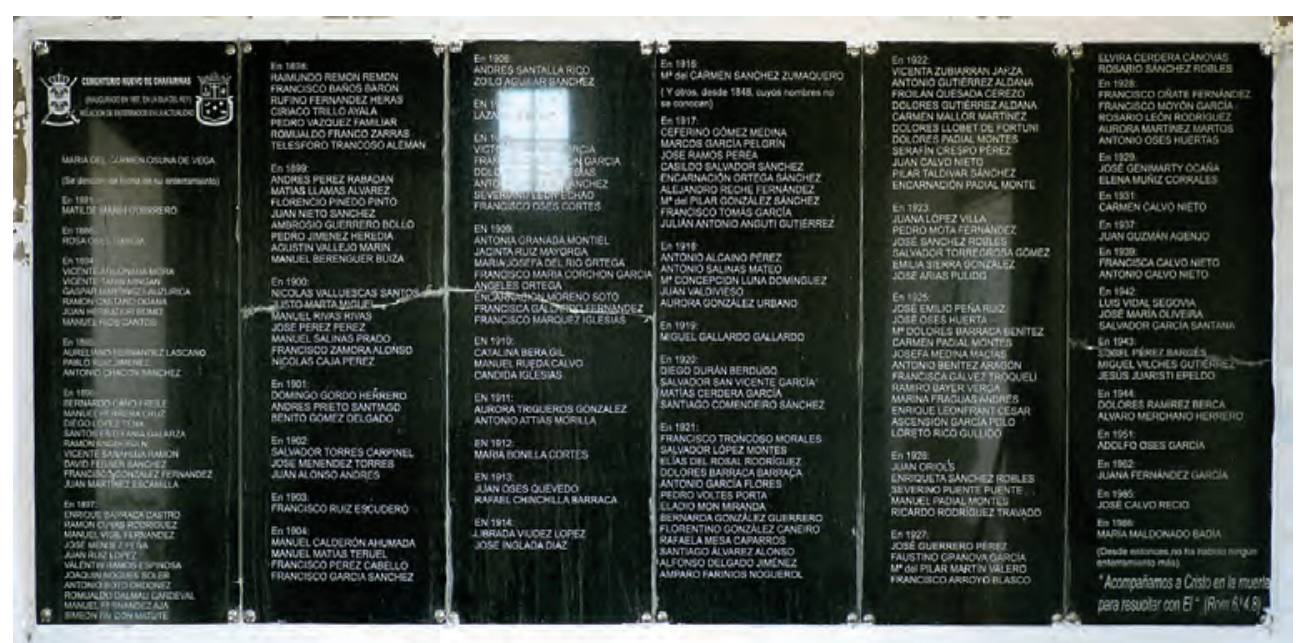

Placa en el interior del cementerio que recuerda todos los nombres de los enterrados en las islas.

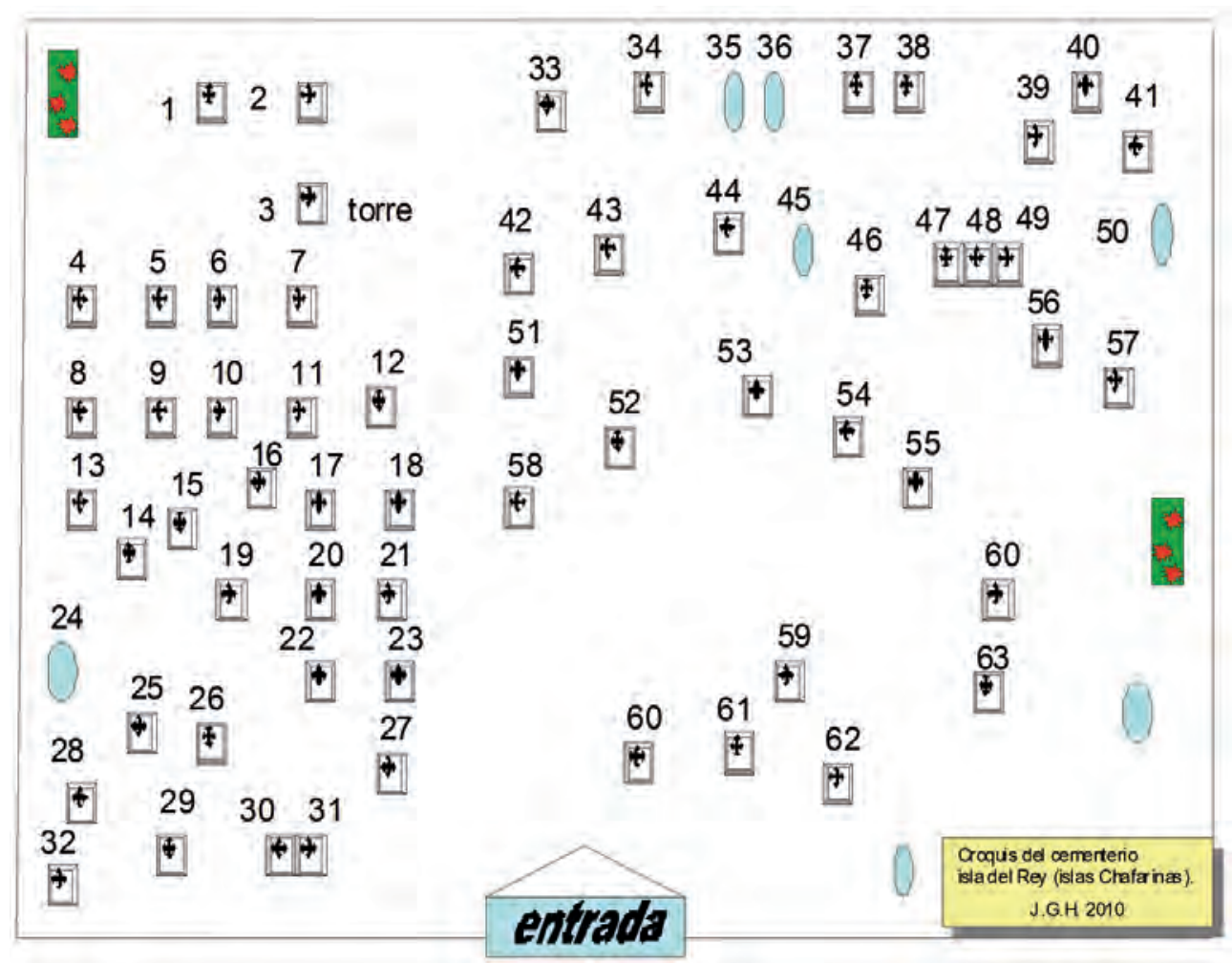

Croquis con la situación de las sepulturas en el cementerio. 

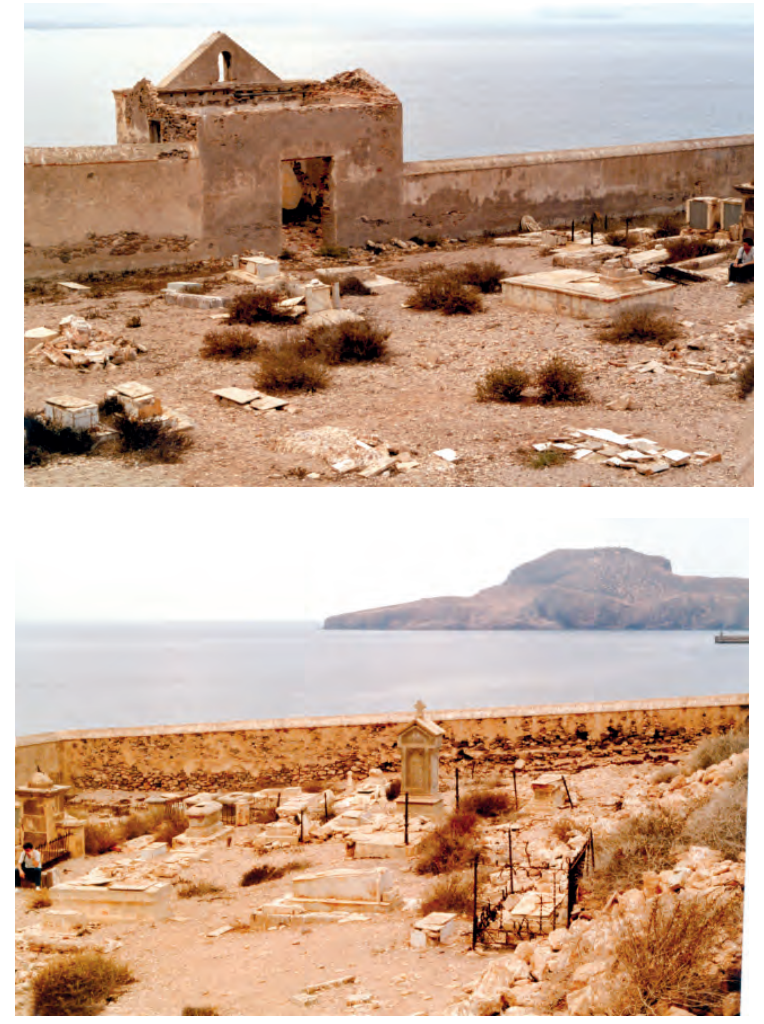

Imágenes del interior del cementerio en 1986.

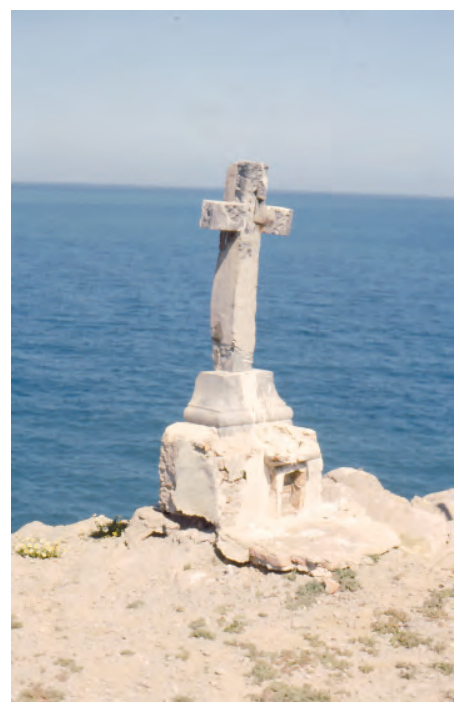

En otros lugares de las islas se levantaron recuerdos a militares fallecidos, como esta cruz que estaba junto a los acantilados al norte de Isabel II. 